\title{
2-Deoxy-D-glucose Mediates Dihydrodiol Dehydrogenases Over-expression and Cisplatin Resistance in Human Cervical Cancer Cells
}

\author{
Jianli Chen ${ }^{1,2, *}$, Rong Wu ${ }^{1,2}$, John Zihou Chen ${ }^{3}$, Visitacion Pabicon², Monika Wrzolek ${ }^{2}$, \\ Fiona Simpkins ${ }^{4}$, Henry Simpkins ${ }^{1,2}$ \\ ${ }^{1}$ The Feinstein Institute for Medical Research, Northwell Health, Manhasset, New York, the United States \\ ${ }^{2}$ Department of Pathology, Staten Island University Hospital of Northwell Health, Staten Island, New York, the United States \\ ${ }^{3}$ Jericho High School, Long Island, New York, the United States \\ ${ }^{4}$ Gynecologic Oncology, Pennsylvania Perelman Center for Advanced Medicine, Philadelphia, Pennsylvania, the United States
}

Email address:

jchen3@northwell.edu (Jianli Chen)

*Corresponding author

\section{To cite this article:}

Jianli Chen, Rong Wu, John Zihou Chen, Visitacion Pabicon, Monika Wrzolek, Fiona Simpkins, Henry Simpkins. 2-Deoxy-D-glucose Mediates Dihydrodiol Dehydrogenases Over-expression and Cisplatin Resistance in Human Cervical Cancer Cells. American Journal of Biomedical and Life Sciences. Vol. 7, No. 5, 2019, pp. 110-120. doi: 10.11648/j.ajbls.20190705.13

Received: September 30, 2019; Accepted: October 14, 2019; Published: October 23, 2019

\begin{abstract}
Dihydrodiol dehydrogenases (DDHs) belong to a superfamily of cytosolic NADP (H)-dependent oxidoreductases. The over-expression of DDHs induces cisplatin resistance. 2-Deoxy-D-glucose (2-DG), a glucose analogue, is currently being used as an anticancer reagent. In this study we investigated the effect of 2-DG on DDHs expression and cisplatin resistance in human cervical cancer 2008 and C13 cells. We employed RT-PCR to detect mRNA level of DDH1, DDH2, and DDH3 and western blotting for protein expression. The cisplatin resistance was investigated with MTT and colony formation assays. Apoptosis/necrosis and mitochondrial membrane potential analysis were evaluated with flow cytometry. The intracellular ROS regulation was evaluated with $\mathrm{H}_{2}$ DCFDA probe. We used 2-DG resistant cells to demonstrate the effect of 2-DG on DDHs expression and cisplatin resistance. 2-DG significantly up-regulated the mRNA level and protein expression of DDH1, DDH2, and DDH3, which consequently increased cisplatin resistance as confirmed by MTT and colony formation assays. In the 2DG-resistant cells, the apoptosis/necrosis percentage and intracellular ROS were significantly decreased. 2-DG itself could activate JNK. When treating the cells combined with cisplatin, 2-DG attenuated cisplatin-mediated JNK phosphorylation. 2DG down-regulated wild-type p53 protein expression at lower 2-DG concentrations (1/2 IC50 and IC50) at 24-hour. Activated JNK attenuation and decreased p53 expression by 2-DG implied the underlying resistance mechanism. Our study highlighted that 2-DG, as an anticancer reagent currently, could be a two-side sword that also significantly inhibited apoptosis by upregulating DDHs expression and consequently increased cisplatin resistance in the human cervical cancer cells we used.
\end{abstract}

Keywords: Cisplatin Resistance, Dihydrodiol Dehydrogenases, 2-Deoxy-D-glucose, Cancer Cells

\section{Introduction}

2-DG is a synthetic analogue of glucose. It can go into the glucose metabolic pathway and competitively inhibit hexokinase, which will affect intracellular glucose metabolism and ATP production. In recent decade, singly or in combination with other cytotoxic chemotherapeutic drugs, 2-DG has been widely used as an anticancer reagent in vitro or in some phase I/II clinical trials [1-3]. Even though the preliminary results from clinical trials were kind of discouraging, many researches are still going on to continuously report that 2-DG can significantly induce apoptosis, increase chemosensitivity, and even reverse drug resistance in different solid tumor and leukemia/lymphoma in vitro [5-10]. On the other hand, up to now only one report found that 2-DG was associated with P-glycoprotein (P-gp) 
over-expression in hepatoma cells, which might imply the unknown side of 2-DG in conferring the phenotype of multiple drug resistance (MDR) in cancer cells [4].

P-gp was known to be mainly associated with plant alkaloids resistance but not to cisplatin. To our knowledge, only one study reported that cisplatin could induce P-gp expression in animal cells but this never got confirmed in human cells [11]. As yet it is not clear whether 2-DG can induce cisplatin resistance. Cisplatin and carboplatin are amongst the most widely used drugs for the treatment of patients with solid tumors and are curative for most patients with germ cell tumors. They are currently widely used in standard chemotherapy protocols for the treatment of patients with ovarian, bladder, cervical, head and neck and lung cancers. However, the intrinsic and/or acquired resistance to these platinum compounds has increasingly become a main problem for successful management of these patients. Our previous studies demonstrated that the cytosolic enzyme DDHs were implicated in producing resistance to cisplatin [12-14]. Transfections of DDH cDNA sequences (primarily the DDH-1 isoform) into a whole series of human cancer cell lines derived from different primary tumors (ovary, cervix, germ cell, and lung) similarly produced cisplatin resistance [15] and its down-regulation with siRNAs correspondingly sensitized resistant cancer cells to cisplatin [13]. A small clinical study with human cervical cancer specimens employing immunohistochemistry showed that DDH expression may be associated with chemotherapy resistance [16]. And over-expression of DDH was even reported as a prognostic marker in non-small cell lung cancer [17].

In this study we investigated the effect of 2-DG on the expression of DDHs and cisplatin resistance. Our results demonstrated that 2-DG could mediate over-expression of DDHs, attenuation of both intracellular ROS and cisplatininduced JNK activation, down-regulation of nuclear p53, and over-expression of many other drug resistance related gene candidates, for example GRP78, HO-1, etc. To our knowledge this is the first study that 2-DG could induce cisplatin resistance, at least for sure in these human cervical cancer cells we used. Therefore, not only P-gp for MDR in hepatoma cells [4], 2-DG can also induce many other genes, for example DDHs, to mediate cisplatin resistance.

\section{Materials and Methods}

\subsection{Cell Culture Reagents and Drugs}

Cell culture reagents and gentamycin were obtained from Cellgro (Herndon, VA) and RNAzol B from Tel-Test Inc. (Friendswood, TX). The cisplatin-sensitive and cisplatinresistant human cervical cancer 2008 and $\mathrm{C} 13$ cell lines were grown in RPMI-1640 medium supplemented with $10 \%$ fetal bovine serum and gentamycin at a final concentration of $10 \mu \mathrm{g} / \mathrm{ml}[12,13]$. Cisplatin and 2-DG were purchased from Sigma-Aldrich Chemical Co. (St. Louis, MO). JC-1 (5, 5', 6, 6' - Tetrachloro-1, 1', 3, 3' -tetraethylbenzimidazolycarbocyanine iodide) was purchased from AnaSpec (Fremont, CA). Annexin
V-FITC apoptosis detection Kit I was purchased from BD Biosciences (Franklin Lakes, NJ).

\subsection{MTT Assay and Colony Formation Assay (CFA)}

Cell cytotoxicity assays [18] were performed as described previously. Briefly, for MTT assay, 4000 Cells were seeded into 96-well plates in triplicates with different concentrations $(0,0.5,1,2,5,10,20,50 \mu \mathrm{M})$ of cisplatin and incubated for 72 hours. $10 \mu \mathrm{l}$ of MTT $(5 \mathrm{mg} / \mathrm{ml})$ was added into each well and incubated for 5 hours at the end of the 72-hour incubation. The plates were read at $590 \mathrm{~nm}$ with a 96 -well plate reader. For CFA, 200 Cells were seeded into 6-well plates and incubated for 24 hours. After treated with different concentrations $(0,0.1$, $0.2,0.5,1,1.5,2,5,10 \mu \mathrm{M})$ of cisplatin for 4 hours, cells were washed twice and added fresh medium and followed by twoweek incubation to allow colony growth. At the end of incubation period, cells were fixed and stained with $0.5 \%$ methylene blue in $50 \%$ ethanol for 40 minutes at room temperature. Thereafter, the plates were gently washed with water and allowed to air-dry. Visible colonies (containing 50 or more cells each) were counted to determine the percent colony formation for drug treatment. IC50 values were calculated and expressed as the mean $\pm \mathrm{SD}$ (standard deviation) from at least three separate triplicate experiments.

\subsection{Apoptosis/Necrosis and Mitochondrial Membrane Potential Analysis}

Apoptosis/necrosis was determined as described in the Annexin V-FITC apoptosis detection Kit I. Cells (1x 10 $\left.{ }^{5}\right)$ were pre-incubated in $500 \mu \mathrm{l}$ of complete RPMI-1640 medium for 24 hours in a 24-well plate. Cisplatin was added and incubated for another 24 hours. Then the cells were trypsinized and harvested and washed with HBSS buffer. The stained cells with Annexin and PI probes were analyzed on BD FACSCalibur with excitation wavelength $488 \mathrm{~nm}$ : emission wavelength $525 \mathrm{~nm}$ for annexin V and $575 \mathrm{~nm}$ for PI.

To evaluate mitochondrial membrane potential depolarization occurring during cellular apoptosis, cells $(1 \mathrm{x}$ $10^{5}$ ) were pre-incubated in $500 \mu 1$ of complete RPMI-1640 medium for 24 hours in a 24-well plate. Cisplatin was added at different concentration $(0,20,50,100 \mu \mathrm{M})$ and incubated for 24 hours and JC-1 (final concentration at $10 \mu \mathrm{M}$ ) added $30 \mathrm{~min}$ prior to the end of the incubation. The medium was aspirated, the cells trypsinized $(0.05 \%$ trypsin-EDTA $)$, centrifuged and the pellets washed and resuspended in HBSS buffer and analyzed with a BD FACSCalibur (excitation wavelength $525 \mathrm{~nm}$ : emission wavelength $575 \mathrm{~nm}$ ).

\subsection{Intracellular ROS Change by 2-DG-induced DDHs}

For estimation of intracellular ROS levels, a cell membrane permeable and oxidant-sensitive fluorescent dye $\mathrm{H}_{2}$ DCFDA was employed [13]. $\mathrm{H}_{2}$ DCFDA, by itself, is non-fluorescent, but once inside the cells is hydrolyzed to $\mathrm{H}_{2} \mathrm{DCF}$ by nonspecific esterases. The $\mathrm{H}_{2}$ DCFDA is a ROS sensitive intermediate whose degradation by intracellular hydrogen peroxides results in generation of fluorescent DCF [29]. Briefly, $4 \times 10^{4}$ cells were 
seeded in 96-well plates for 24-h incubation. Thereafter, the growth medium was aspirated and $100 \mu 1$ of warm $\left(37^{\circ} \mathrm{C}\right.$ water bath-preincubated) HBSS buffer ( $\mathrm{pH} 7.4)$ and $\mathrm{H}_{2}$ DCFDA was added to each well (final concentration at $25 \mu \mathrm{M}$ ) and incubated further at $37^{\circ} \mathrm{C}$ for $30 \mathrm{~min}$. The cells were then washed with warm HBSS twice and the generation of ROS (measured as fluorescence intensity) was measured on a multi-well fluorescence microplate reader (TECAN GENios, Durham, NC) with an excitation wavelength of $485 \mathrm{~nm}$ and an emission wavelength of $535 \mathrm{~nm}$. The data were expressed as fluorescent intensity per $4 \times 10^{4}$ cells [13].

\subsection{Semi-Quantitative RT-PCR Analysis}

Total RNA was isolated from the cells after twice wash with cold PBS (pH 7.4). RNAzol (Tel-test, Friendswood, TX) was added followed by chloroform extraction, isopropanol precipitation, and a $75 \%(\mathrm{v} / \mathrm{v})$ ethanol-DEPC wash. The reverse transcription reaction consisted of $1 \mu \mathrm{g}$ of RNA, 4 units of Omniscript RT, $1 \mu \mathrm{M}$ oligo-dT primer, $0.5 \mathrm{mM}$ dNTP, 10 units of RNase inhibitor, and 1 x RT buffer. Reverse transcription was performed at $37^{\circ} \mathrm{C}$ for $1 \mathrm{~h}$ and inactivated at $93^{\circ} \mathrm{C}$ for $3 \mathrm{~min}$. The cDNA was then amplified by PCR using gene specific primer pairs. Each PCR consisted of 1 x PCR buffer, $1.5 \mathrm{mM} \mathrm{MgCl}$, $200 \mu \mathrm{M}$ dNTP, 2.5 units of Taq Polymerase and $0.2 \mathrm{mM}$ genespecific forward (F) and reverse (R) primers. The PCR conditions were as follows: an initial denaturation at $94^{\circ} \mathrm{C}$ for $15 \mathrm{~s}, 55^{\circ} \mathrm{C}$ for $30 \mathrm{~s}, 72^{\circ} \mathrm{C}$ for $30 \mathrm{~s}$ for the number of cycles optimized for each primer to ensure that the product intensity fell within the linear phase of amplification, and then a final elongation step was performed for $10 \mathrm{~min}$ at $72^{\circ} \mathrm{C}$. RT-PCR amplification of GAPDH was used as internal control to verify that equal amounts of RNA were used from each cell line. All primer sequences are as follows [13]:

\section{DDH-1: F 5'-CTAACCAGGCCAGTGACAGA-3', R 5'-CTCATGCAATGCCCTCCATG-3'; \\ DDH-2: F 5'-GCTAACCAGGCCAGTGACAGAAATG-3', R 5'-CTTCTGGCAGACCTCATGCAATG-3'; \\ DDH-3: F 5'-CCCATTGTTTTTGTAATCTCTG-3', R 5'-TTATTTCAAAATGATAAAAATTTATTG-3'; GAPDH: F 5'-GAAGGTGAAGGTCGGAGTC-3', R 5'-GAAGATGGTGATGGGATTC-3'.}

\subsection{Western Blotting Analysis}

Cells at a density of $1 \times 10^{6} / \mathrm{ml}$ were incubated under normal growth conditions and then washed with chilled PBS (3x) and a whole cell lysate prepared from each of the cell lines by scraping the cells into a buffer containing $20 \mathrm{mM}$ Tris- $\mathrm{HCl} \mathrm{pH} 7.5,150$ $\mathrm{mM} \mathrm{NaCl}, 1 \mathrm{mM}$ EDTA, 1mM EGTA, $1 \%$ (v/v) Triton X-100, $0.5 \%$ (v/v) Nonidet P40, $2.5 \mathrm{mM}$ sodium pyrophosphate, $1 \mathrm{mM}$ sodium orthovanadate, $50 \mathrm{mM}$ sodium fluoride and $1 \mathrm{x}$ protease inhibitor cocktail and incubated on ice for $30 \mathrm{~min}$. The lysate was then centrifuged at $13,000 \mathrm{~g}$ for $10 \mathrm{~min}$ and the supernatant was transferred to a fresh tube and stored at $-80^{\circ} \mathrm{C}$ until use. Nuclear protein extraction for $\mathrm{p} 53$ followed the manual instructions of Nuclear Extraction Kit (Millipore, MA). Proteins (10 or 30 $\mu \mathrm{g}$ ) were loaded and separated by SDS-PAGE and were transferred to a PVDF membrane. The different antibodies were applied (at concentrations described by the manufacturer) to the PVDF membrane and the bands identified by enhanced chemiluminescence reagents (Pierce Biochemicals, Rockford, IL). The antibodies utilized were goat polyclonal GRP78, rabbit polyclonal JNK, phospho-JNK (Santa Cruz BiotechnologySanta Cruz, CA), DDH-1 and DDH-2 mouse polyclonal antibodies (Abnova Corp. -Walnut, CA), mouse monoclonal p53 (St. Louis, MO) and mouse monoclonal actin (Ab-1) (Calbiochem-San Diego, CA) and a DDH-3 mouse monoclonal antibody (Abcam -Cambridge, MA). Anti-NF-YA polyclonal antibody and the secondary antibodies were anti-goat, anti-rabbit, and anti-mouse (Pierce Biotechnology-Rockford, IL). Densitometry analysis was done with Image J software.

\subsection{Statistical Analysis}

The linear regression analysis and paired t-test were performed using the SigmaStat Statistical Analysis System, Version 1.01. $\mathrm{P}<0.05$ was considered significant.

\section{Results}

\subsection{Growth Inhibition by 2-DG Treatment}

Similar to other study [1], our results also found 2-DG inhibited the growth of these sensitive and resistant human cervical cancer cells. When the maximal physiological concentration (8.88mM in RPMI-1640 medium [19]) of 2DG was administered, the growth inhibition was even more significant than that by cisplatin at $2 \mu \mathrm{M}$ in sensitive 2008 cells or at $20 \mu \mathrm{M}$ in resistant $\mathrm{C} 13$ cells (Figure $1 \mathrm{a}, 1 \mathrm{~b}$ ). When $2 \mathrm{mM}$ and $4 \mathrm{mM}$ of 2-DG were used in combination with cisplatin, IC50s of cisplatin by MTT assay would be decreased by 2-3 times in 2008 cells or by 6-16 times in C13 cells (Table 1). These findings suggested that 2-DG could significantly inhibit the growth of these cells and increase their sensitivity to cisplatin. Interestingly, the resistant C13 cells were even more significantly inhibited at the same concentration $(2 \mathrm{mM}$ or $4 \mathrm{mM})$ when compared with the parental sensitive 2008 cells. This phenomenon was also observed in other study [29] and was believed to be associated with the higher proliferation rate in the resistant cells than in sensitive cells. IC50 of 2-DG in 2008 by MTT assay was $2.5 \mathrm{mM}$ but in C13 $3.3 \mathrm{mM}$, with only $0.8 \mathrm{mM}$ difference between these two cell lines.

Table 1. Effect of 2-DG on the IC50 values determined by MTT assay. The values presented from at least three independent experiments, each performed in triplicate. The degree of resistance was calculated as the ratio of cisplatin IC50 value of every group over the cisplatin IC50 value of 2008 and C13 cells. Data are expressed as mean $\pm S . D .{ }^{*} P<0.05$ vs parental group.

\begin{tabular}{lll}
\hline cells/drugs & IC50 $($ mean \pm S.D. $)$ & Fold resistance \\
\hline 2008 & $1.3 \pm 0.2$ & 1 \\
2008/cisplatin+2-DG $(2 \mathrm{mM})$ & $0.5 \pm 0.1$ & $0.4^{*}$ \\
2008/cisplatin+2-DG $(4 \mathrm{mM})$ & $0.4 \pm 0.1$ & $0.3^{*}$ \\
C13 & $8.4 \pm 0.3$ & 6.4 \\
C13/cisplatin+2-DG $(2 \mathrm{mM})$ & $1.8 \pm 0.2$ & $1.4^{*}$ \\
C13/cisplatin+2-DG $(4 \mathrm{mM})$ & $0.5 \pm 0.1$ & $0.4^{*}$ \\
\hline
\end{tabular}



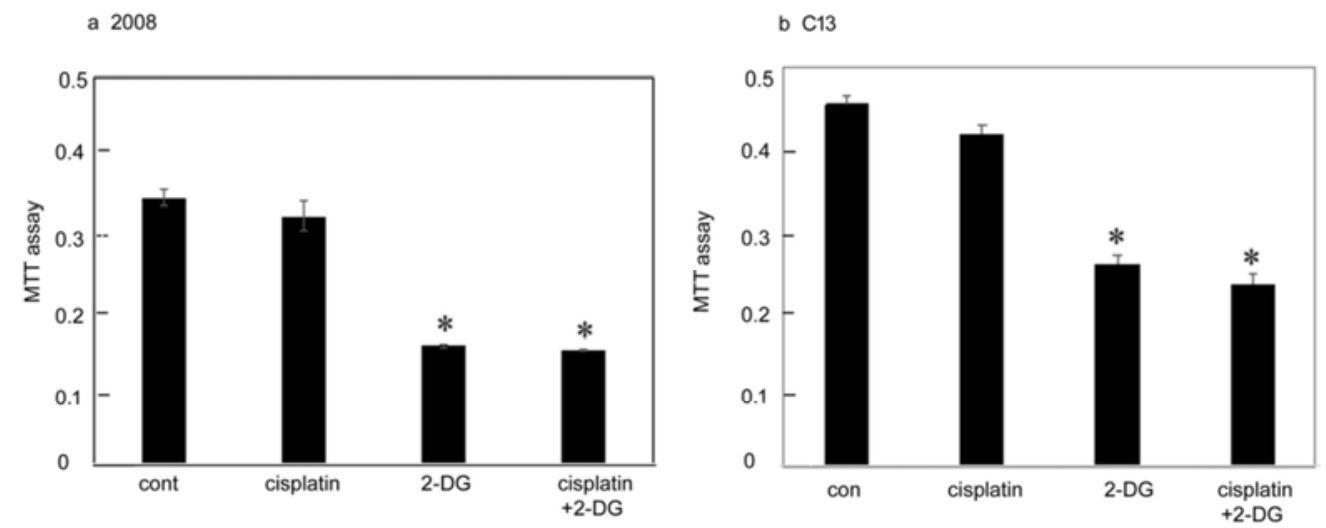

Figure 1. Growth inhibition of 2008 and C13 cells with 2-DG (8.88mM) treatment. Y axis stands for optical density evaluated by MTT assay at $590 \mathrm{~nm}$. a. 2008 cells: $2 \mu M$ cisplatin; b. C13 cells: $20 \mu M$ cisplatin. The values presented as the mean $\pm S D$ and are from three independent experiments with each performed in triplicate. ${ }^{*} P<0.01$ compared with the control.

\subsection{Up-regulation of $m R N A$ and Protein Expression of DDHs by 2-DG in both Time-dependent and Dose-dependent Modes}

Our previous studies have found that DDH1, DDH2, and DDH3 are associated with cisplatin resistance in many cancer cell lines with different tissue origins [12, 14]. Over-expression of DDH1-3 by full-length cDNA transfections increased cisplatin resistance but knockdown of DDHs with siRNAs decreased cisplatin resistance $[12,13]$. Here we detected the effect of 2-DG on mRNA and protein expression of DDH1-3. We used IC50s of 2-DG (2.5mM for 2008; $3.3 \mathrm{mM}$ for C13) to treat cells for $0,30 \mathrm{~min}, 2 \mathrm{~h}, 6 \mathrm{~h}, 8 \mathrm{~h}, 24 \mathrm{~h}, 48 \mathrm{~h}$, and $72 \mathrm{~h}$. We found that mRNA levels of DDH1-3 were up-regulated by a time-dependent mode in both 2008 and $\mathrm{C} 13$ cells (Figure 2a, $2 b$ ). Also, we treated cells with $0,1 / 8$ of, $1 / 4$ of, $1 / 2$ of IC50, IC50, and $8.88 \mathrm{mM}$ (maximal physiological concentration) of
2-DG for 6 hours. Our results showed the similar finding that mRNA levels of DDH1-3 were also increased by a dosedependent mode in both cells (Figure 2c, 2d). To compare with the effect of cisplatin on DDHs mRNA, we treated 2008 and C13 cells for 6 hours with different concentrations of cisplatin. Surprisingly, we found cisplatin could only slightly upregulate DDH1mRNA in 2008 at a relatively higher concentration of cisplatin $(20 \mu \mathrm{M}$ in 2008 cells) but no mRNA change was found in $\mathrm{C} 13$ cells even at as high as $100 \mu \mathrm{M}$ of cisplatin (Figure 2e, 2f). These findings implied that 2-DG was more easily than cisplatin to increase the expression of DDHs. Likewise, we treated cells in a similar way to check DDH1-3 expression by western blotting and we got the very similar results showing DDH1-3 expression was consistently upregulated by $2-\mathrm{DG}$ in a time- or a dose-dependent mode in these cells (Figure 3a, b, c, d).
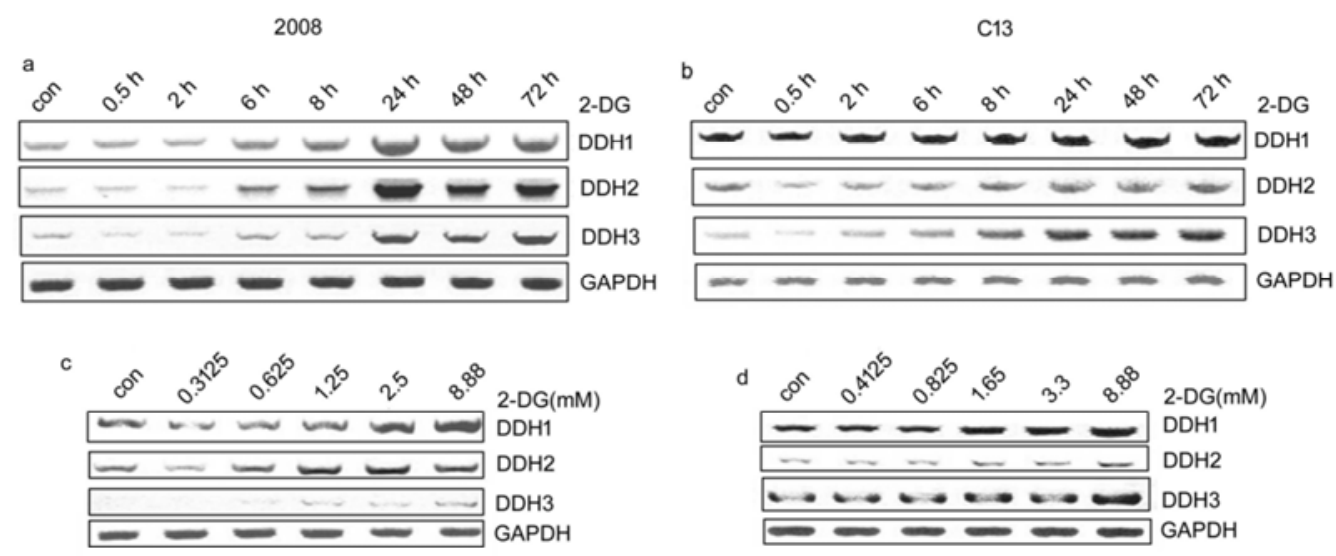

e
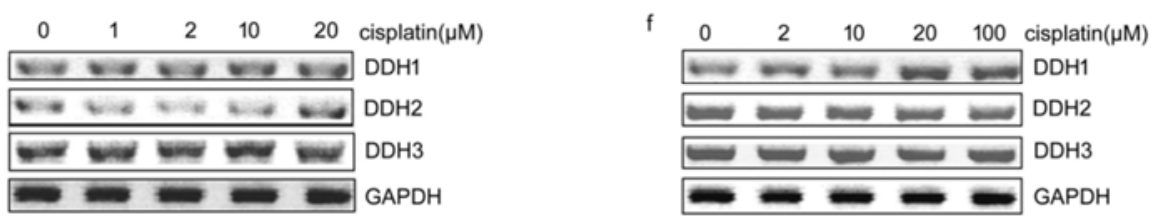

Figure 2. RT-PCR analysis of DDHs mRNA level in 2008 and C13 cells. DDH1-3 mRNA level starting elevated 6 hours after treatment with 2-DG at 2.5 mM for 2008 cells (a) and at $3.3 \mathrm{mM}$ for C13 cells (b) by a time-dependent mode; Up-regulation of DDHs mRNA level at different concentrations of 2-DG for 6hour treatment in 2008 cells (c) and in C13 cells (d) by a dose-dependent mode. For comparison, the effect of cisplatin on DDHs mRNA at different concentrations in 2008 cells (e) and in C13 cells (f). 


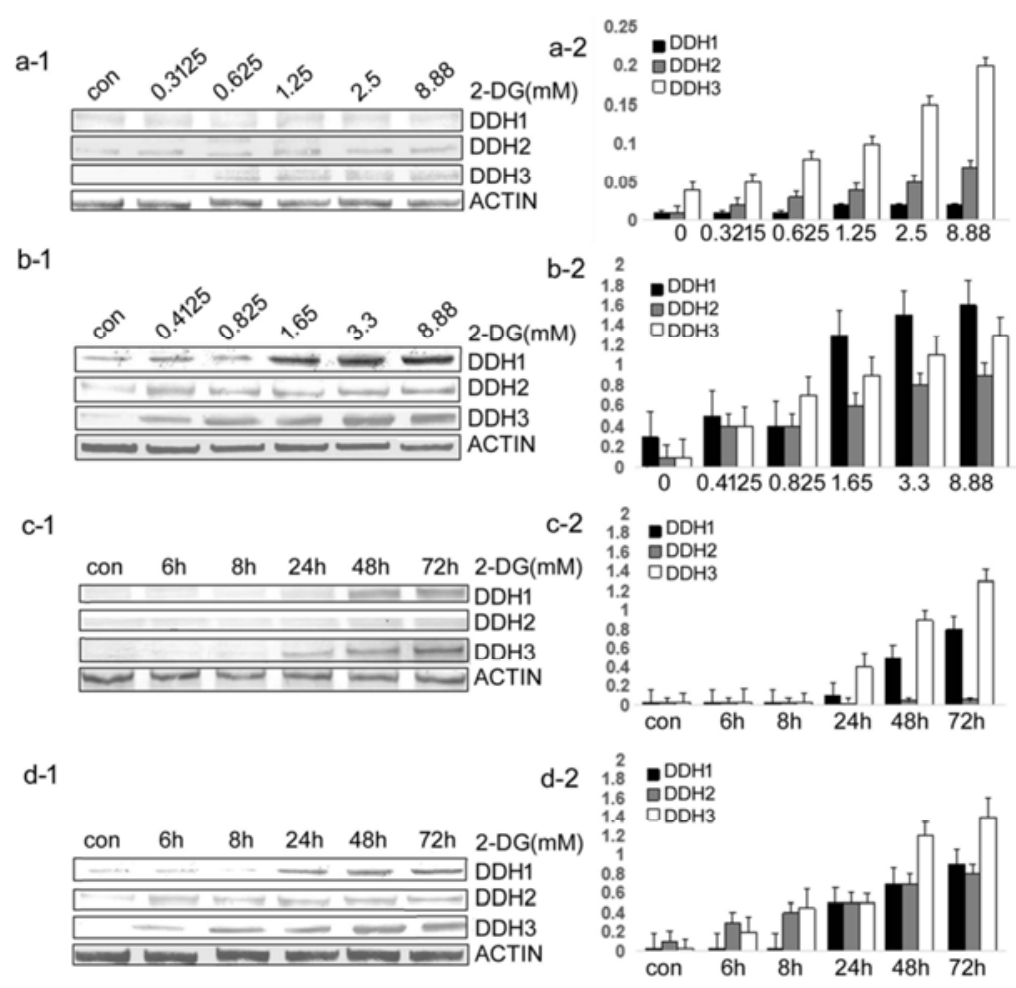

Figure 3. Western blotting analysis of DDHs expression by 2-DG in 2008 and C13 cells. Up-regulation of DDH1-3 expression with treatment of 2-DG at timedependent and dose-dependent modes in 2008 cells (a1-2, c1-2, bands and densitometry) and C13 (b1-2, d1-2, bands and densitometry) cells; a and $b$ were after 24-hour treatment with 2-DG; c and d were treated with 2-DG at $2.5 \mathrm{mM}$ in 2008 cells and $3.3 \mathrm{mM}$ in C13 cells.

a

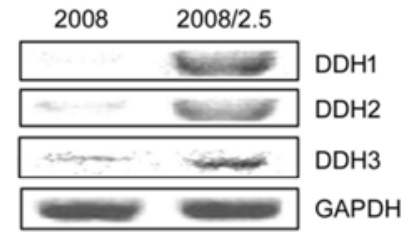

c-1

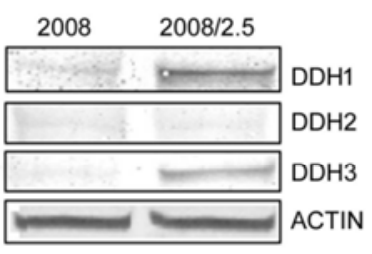

d-1

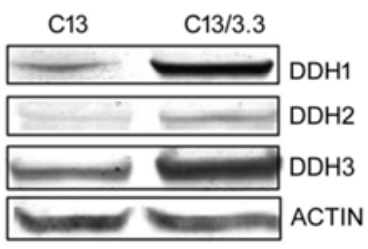

b
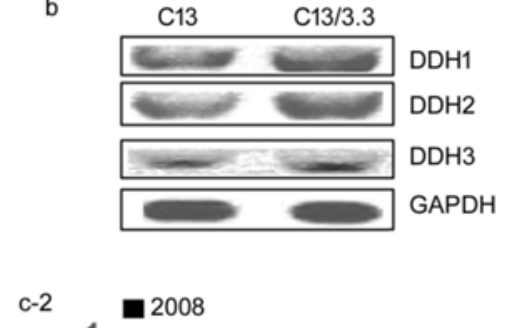

$1 \square 2008 / 2.5$

0.8

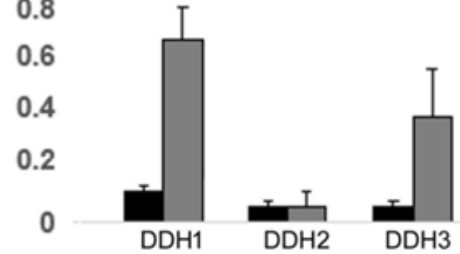

d-2 $2 \quad \mathbf{C} 13$

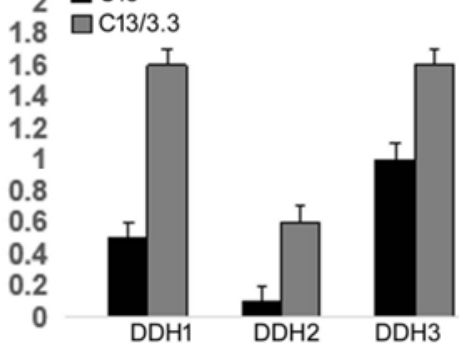

Figure 4. 2-DG increased DDH1-3 mRNA level and protein expression in 2-DG-resistant cells. DDH1-3 mRNA were quantified by RT-PCR: (a) 2008 and 2008/2.5mM cell lines; (b) C13 and C13/3.3mM cell lines. DDH1-3 protein expression by western blotting (c1-2. bands and densitometry; d1-2. bands and densitometry) in their parental and 2-DG resistant cells.

In view of the possibility that the up-regulation of DDH1-3

might be a reversible short-term event, we continuously 
treated 2008 and $\mathrm{C} 13$ cells at $2.5 \mathrm{mM}$ and $3.3 \mathrm{mM}$ of $2-\mathrm{DG}$ respectively for 6 month until they could stably grow in RPMI-1640 medium with 2-DG. We named these cells as 2008/2.5mM and C13/3.3mM. Their growth doubling cycles were similar to those of their parental cells. We checked mRNA levels (Figure 4a, 4b) and protein expression of DDH1-3 (Figure 4c, 4d), and found the up-regulation of DDH1-3 was stably confirmed in these cells.

\subsection{2-DG-mediated Over-expression of DDHs Increases Cisplatin Resistance}

To evaluate the effect of 2-DG on cisplatin sensitivity, we investigated the cytotoxicity of $2008,2008 / 2.5 \mathrm{mM}, \mathrm{C} 13$, and $\mathrm{C} 13 / 3.3 \mathrm{mM}$ cells to cisplatin by MTT and colony formation assays. These assays gave us very similar results that 2008/2.5mM cells showed increased cisplatin resistance by 2 times and $\mathrm{C} 13 / 3.3 \mathrm{mM}$ cells by 1.5 times when comparing with their parental cells. Based on our previous study results that over-expression of DDHs is consistently associated with increased cisplatin resistance $[12,13,15]$, our current results clearly suggested that 2-DG up-regulated DDH1-3 expression, which consequently caused an increase of cisplatin resistance based on the significant increasing change of IC50s of cisplatin in these 2-DG-resistant cells by both MTT and CFA assays (Table 2a, 2b).

Table 2. Cytosensitivity comparison between 2-DG-resistant cells and parental cells.

\begin{tabular}{llll}
\hline cells $/ 2$-DG & $\begin{array}{l}\text { IC50 }(\boldsymbol{\mu M}) \\
(\mathbf{m e a n} \pm \text { S.D. })\end{array}$ & $\begin{array}{l}\text { Fold } \\
\text { resistance }\end{array}$ & P values \\
\hline 2008 & $1.32 \pm 0.37$ & 1 & \\
$2008 / 2.5 \mathrm{mM}$ & $2.33 \pm 0.11$ & 1.76 & $<0.01^{*}$ \\
$\mathrm{C} 13$ & $8.43 \pm 0.24$ & 6.37 & $<0.01^{*}$ \\
$\mathrm{C} 13 / 3.3 \mathrm{mM}$ & $12.32 \pm 0.83$ & 9.31 & $<0.05^{* *}$ \\
\hline
\end{tabular}

a. IC50 values from MTT assay with cells exposed to cisplatin. When compared with parental cells, 2-DG-resistant cells got increased IC50s and more resistant. *vs 2008 , ** vs C13, p $<0.05$.

\begin{tabular}{llll}
\hline cells $/ 2$-DG & $\begin{array}{l}\text { IC50 }(\boldsymbol{\mu M}) \\
(\text { mean } \pm \text { S.D. })\end{array}$ & $\begin{array}{l}\text { Fold } \\
\text { resistance }\end{array}$ & P values \\
\hline 2008 & $0.3 \pm 0.06$ & 1 & \\
$2008 / 2.5 \mathrm{mM}$ & $0.63 \pm 0.05$ & 2.11 & $<0.05^{*}$ \\
$\mathrm{C} 13$ & $2.07 \pm 0.05$ & 6.93 & $<0.01^{*}$ \\
$\mathrm{C} 13 / 3.3 \mathrm{mM}$ & $3.11 \pm 0.09$ & 10.39 & $<0.01^{* *}$ \\
\hline
\end{tabular}

b. IC50 values with CFA assay. The results showed 2-DG-resistant cells more resistant to cisplatin. *vs $2008, * *$ vs C13, p $<0.05$.

Table 3. Apoptosis/necrosis induced by NAC and cisplatin.

\begin{tabular}{lll}
\hline cells & $\mathbf{2 0 0 8}(\%)$ & C13 (\%) \\
\hline cont & $2.52 \pm 0.81$ & $1.53 \pm 0.46$ \\
5mM 2-DG & $2.76 \pm 1.31$ & $1.26 \pm 0.78$ \\
8.88mM 2-DG & $2.88 \pm 1.27$ & $1.58 \pm 0.64$ \\
5mM 2-DG+5mM NAC & $68.56 \pm 3.57 *$ & $79.64 \pm 2.89 * *$ \\
8.88mM 2-DG+5mM NAC & $76.76 \pm 2.43 *$ & $82.78 \pm 3.47 * *$ \\
\hline
\end{tabular}

a. NAC-induced apoptosis/necrosis. Cells were treated with 2-DG at $5 \mathrm{mM}$ or $8.88 \mathrm{mM}$ with and without NAC $5 \mathrm{mM}$ for 24 hours. Data are expressed as mean \pm S.D. from three-time independent experiments. * vs 2008; ** vs C13. $\mathrm{P}<0.05$.

\begin{tabular}{lll}
\hline cells/cisplatin $(\boldsymbol{\mu M})$ & apoptosis/necrosis $(\%)$ & P values \\
\hline $2008 / 50$ & $23.36 \pm 2.55$ & \\
$(2008 / 2.5 \mathrm{mM}) / 50$ & $10.86 \pm 2.39$ & $<0.05^{*}$ \\
$\mathrm{C} 13 / 50$ & $1.82 \pm 0.21$ & \\
$(\mathrm{C} 13 / 3.3 \mathrm{mM}) / 50$ & $1.88 \pm 0.18$ & $>0.05^{* *}$ \\
$\mathrm{C} 13 / 400$ & $15.3 \pm 2.08$ & $<0.05^{* *}$ \\
$(\mathrm{C} 13 / 3.3 \mathrm{mM}) / 400$ & $7.42 \pm 3.11$ & $<0.05^{* *}$ \\
\hline
\end{tabular}

b. Cisplatin-induced apoptosis/necrosis in 2-DG-resistant cells. Cells were treated with cisplatin at $50 \mu \mathrm{M}$ or $400 \mu \mathrm{M}$ for 24 hours. Data are expressed as mean \pm S.D. from at least three-time independent experiments. * vs 2008; ** vs C13. $\mathrm{p}<0.05$ as significant.

\subsection{Decreased Intracellular ROS Level in 2-DG-resistant 2008 and C13 Cells}

Functional cytosolic DDHs attenuate intracellular ROS level [13]. To see whether 2-DG-resistant 2008/2.5mM and C13/3.3mM cells express functional DDHs attenuating intracellular ROS, we checked their intracellular ROS level with $\mathrm{H}_{2}$ DCFDA probe. The results suggested that with the increasing DDHs expression there were corresponding lower intracellular ROS levels in $2008 / 2.5 \mathrm{mM}$ and $\mathrm{C} 13 / 3.3 \mathrm{mM}$ cells when compared with their parental 2008 and C13 cells [Table 4]. This change of intracellular ROS level was completely compatible with our previous finding that intracellluar ROS level was inversely associated with cytosolic DDHs level.

Table 4. Intracellular ROS levels in 2-DG-resistant cells. For intracellular ROS detection, 25uM of $\mathrm{H}_{2} \mathrm{DCFDA}$ was employed for 6-hour incubation and read plates with a multi-well fluorescence microplate reader (TECAN GENios) at an excitation wavelength of $485 \mathrm{~nm}$ and an emission wavelength of $535 \mathrm{~nm}$. The data are expressed as fluorescent intensity per $2 \times 10^{4}$ cells. *vs 2008, **vs C13.

\begin{tabular}{llll}
\hline Cells & $\begin{array}{l}\text { Intracellular } \\
\text { ROS }\end{array}$ & $\begin{array}{l}\text { \% change (compared } \\
\text { to 2008 cells) }\end{array}$ & $\begin{array}{l}\text { P } \\
\text { values }\end{array}$ \\
\hline 2008 & $38299 \pm 3500$ & $100 \%$ & \\
$2008-2.5 \mathrm{mM}$ & $25882 \pm 5068$ & $67 \%$ & $<0.01^{*}$ \\
$\mathrm{C} 13$ & $29844 \pm 4486$ & $78 \%$ & $<0.05^{*}$ \\
$\mathrm{C} 13-3.3 \mathrm{mM}$ & $18504 \pm 4348$ & $48 \%$ & $<0.05^{* *}$ \\
\hline
\end{tabular}

\subsection{Decreased Apoptosis/Necrosis by 2-DG-mediated DDHs Over-expression}

To further check 2-DG-induced drug resistance and cellular apoptosis, we detected the effect of 2-DG on apoptosis/necrosis in these cells. Firstly we checked the effect of 2-DG alone by treating the cells with $2-\mathrm{DG}$ at 0 , $5 \mathrm{mM}$, and $8.88 \mathrm{mM}$ for 24 hours. We found that 2-DG treatment alone could not induce significant change of apoptosis/necrosis (Table 3a). Simons et al [19] reported that ROS contribute to the toxicity induced by 2-DG alone or in combination with cisplatin. N-acetyl-cysteine (NAC) can inhibit any effect caused by 2-DG in their study. Considering this as a possible reason, we used NAC $(5 \mathrm{mM})$ to evaluate the effect on apoptosis. Surprisingly, our findings showed that NAC did not inhibit but dramatically induced the apoptosis/necrosis in both cells (Table 3a). This is compatible with some reports that NAC could increase apoptosis by direct actions on apoptotic pathways [30] or by endothelial nitric oxide synthase- 
mediated production of nitric oxide [31]. Therefore, our finding does not support the hypothesis that ROS generation upon 2-DG treatment is the underlying factor for inducement of apoptosis/necrosis. Cell type dependence might be the reason for the above discrepancy with other authors.

In addition to the effect of 2-DG alone on apoptosis/necrosis above, we also treated 2008, 2008/2.5mM, $\mathrm{C} 13$, and $\mathrm{C} 13 / 3.3 \mathrm{mM}$ cells with cisplatin at $50 \mu \mathrm{M}$ for 24 hours. Our results suggested that the apoptosis/necrosis rate was significantly decreased in $2008 / 2.5 \mathrm{mM}$ cells $(10.86 \%)$ when compared with that in 2008 cells $(23.36 \%)(\mathrm{P}<0.05)$. No significant apoptosis/necrosis decrease was observed in $\mathrm{C} 13 / 3.3 \mathrm{mM}$ cells when compared with $\mathrm{C} 13$ cells at $50 \mu \mathrm{M}$ cisplatin treatment (Table 3b). However, when we treated with higher concentration of cisplatin $(400 \mu \mathrm{M})$, the apoptosis/necrosis percentage in $\mathrm{C} 13 / 3.3 \mathrm{mM}$ cells showed 2 times less than that in its parental $\mathrm{C} 13$ cells $(7.42 \%$ vs $15.3 \%$, $\mathrm{P}<0.05$ ) (Table 3b).

To double check the effect above, we employed molecular probe JC-1 to detect cellular mitochondrial membrane potentials. When mitochondrial membrane depolarization was measured following 24-hour cisplatin treatment, a good correlation with apoptosis/necrosis was observed. The $2008 / 2.5 \mathrm{mM}$ and $\mathrm{C} 13 / 3.3 \mathrm{mM}$ cell lines showed lower degree of depolarization on cisplatin treatment when compared with those of 2008 and $\mathrm{C} 13$ cells $(35.1 \%$ in 2008 vs $16.76 \%$ in $2008 / 2.5 \mathrm{mM}$ at $50 \mu \mathrm{M}$ of cisplatin; $73.82 \%$ in $\mathrm{C} 13$ vs $56.32 \%$ in $\mathrm{C} 13 / 3.3 \mathrm{mM}$ at $150 \mu \mathrm{M}$ of cisplatin; both $\mathrm{P}<0.05$ ).

\subsection{Phosphorylation of JNK by 2-DG and Its Relationship with DDHs Expression}

To ask the effect of 2-DG on JNK phosphorylation, we treated 2008 and C13 cells with IC50 $(2.5 \mathrm{mM}$ and $3.3 \mathrm{mM}$ respectively) and the maximal physiological concentrations $(8.88 \mathrm{mM})$. Results suggested that 2-DG itself could activate JNK phosphorylation (Figure 5a). Since 2-DG up-regulates DDHs and activates JNK, we asked if JNK phosphorylation was an early event upon 2-DG treatment before the upregulation of DDHs, which might also be one of JNK downstream substrates including ATF-2, c-Jun, Bcl-2, Bcl$\mathrm{XL}, \mathrm{p} 21$, p53, etc [20]. We treated 2008 cells with $10 \mu \mathrm{M}$ of JNK inhibitor SP600125 (Calbiochem, CA). We speculated if JNK inhibitor could inhibit DDH up-regulation, we would know that the up-regulation of DDHs induced by 2-DG is initially mediated by earlier JNK activation. Our results found that JNK inhibitor itself or its solvent DMSO had no any effect on DDH1 expression. However, when treating 2008 cells with 2-DG together, JNK inhibitor could synergistically up-regulate DDH1 expression with 2-DG (Figure 5b). More interestingly, both cisplatin and 2-DG could activate JNK separately, however, when treating cells with 2-DG in combination with cisplatin, 2-DG would attenuate cisplatin-mediated JNK phosphorylation in 2008 cells (Figure 5c). We previously found that JNK phosphorylation was associated with increasing apoptosis in 2008 cells [14], so both the inhibition of cisplatin-induced phosphorylation of JNK and the up-regulation of DDHs by 2DG treatment would definitely contribute to inhibiting apoptosis and increasing cisplatin resistance in these cells.
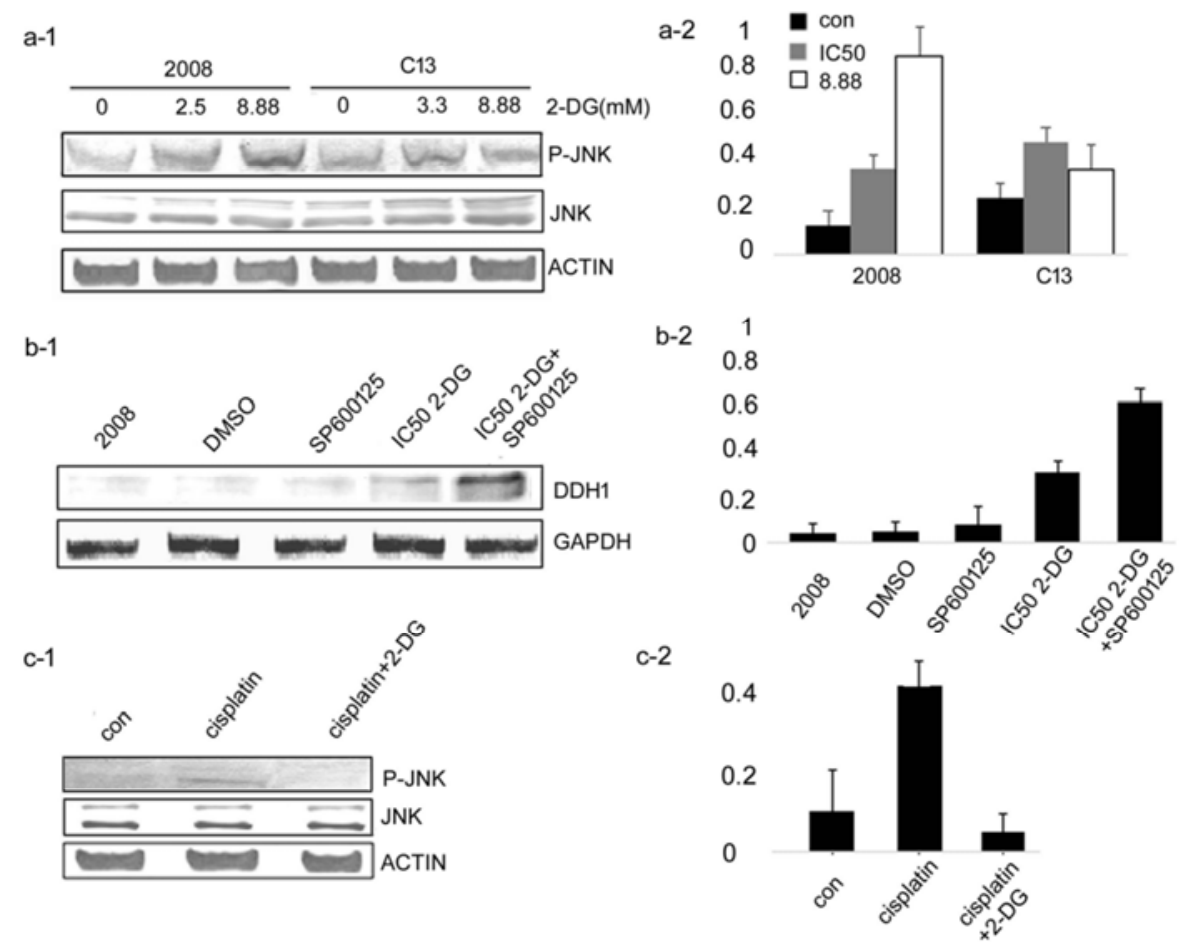

Figure 5. 2-DG activated JNK by western blotting analysis. (a). JNK activation by 2-DG in 2008 cells (lane 1 to 3 ) and C13 cells (lane 4-6), a-1 bands; a-2 densitometry; (b) $10 \mu \mathrm{M} J \mathrm{NK}$ inhibitor SP600125 synergistically up-regulating DDH1 protein expression with 2-DG in 2008 cells, b-1 bands; b-2 densitometry; (c) cisplatin $(100 \mu M)$ activating JNK but 2-DG (2.5 mM) attenuating cisplatin-induced JNK activation in 2008 cells, c-1 bands; c-2 densitometry.

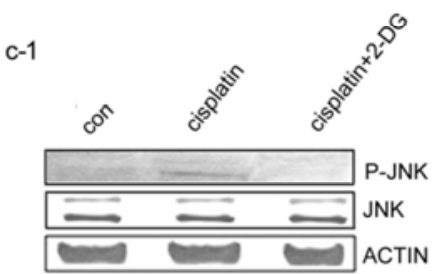




\subsection{Down-regulation of Wild-type p53 Protein by 2-DG Treatment}

Both 2008 and C13 cells express wild-type p53 and cisplatin treatment can significantly up-regulate $\mathrm{p} 53$ protein expression in both cell lines [21]. Since wild-type p53 is widely known to play an important role in apoptosis regulation, we asked if 2-DG singly or in combination with cisplatin also would increase p53 expression. We initially treated 2008 cells with $10 \mu \mathrm{M}$ of cisplatin and $2.5 \mathrm{mM}$ of $2-$ DG for 24 hours. As expected, cisplatin apparently increased p53 expression. However, 2-DG was surprisingly found to down-regulate p53 expression. When treating cells with both 2-DG and cisplatin, cisplatin reversed the inhibiting effect of 2-DG on p53 expression in 2008 cells (Figure 6a). To further investigate this effect, we treated 2008 and $\mathrm{C} 13$ cells with different concentrations $(1 / 2 \mathrm{IC} 50, \mathrm{IC} 50,8.88 \mathrm{Mm})$ of $2-\mathrm{DG}$ for 24 hours and 48 hours respectively. The results interestingly showed a p53 expression decrease in both cell lines at $1 / 2$ IC50 and IC50 concentrations after 24-hour treatment, which is consistent with our preliminary result by 2-DG (at IC50 concentration) in 2008 cells. At higher concentration $(8.88 \mathrm{mM})$ of $2-\mathrm{DG}, \mathrm{p} 53$ expression showed a decrease in sensitive 2008 cells but a significant increase in resistant $\mathrm{C} 13$ cells. However, when the cells were treated for 48 hours, p53 expression increased at lower concentrations ( $1 / 2$ IC50 and IC50) but decreased at higher $8.88 \mathrm{mM}$ (Figure 6b).

p53 is mostly regarded as a nuclear substrate of phosphorylated JNK relocated from cytoplasm after activation [20]. We asked if p53 expression change by 2-DG in our cells was mediated only through JNK pathway. If this was the case in our cells, 2-DG-activated JNK phosphorylation should have increased p53 expression, not the opposite. Furthermore, if JNK inhibitor SP600125 $(10 \mu \mathrm{M})$ was used to treat the cells with 2DG, p53 should have been decreased even more plus the effect from 2-DG. To investigate this hypothesis, we treated 2008 cells with JNK inhibitor SP600125 $(10 \mu \mathrm{M})$ with and without 2-DG ( $2.5 \mathrm{mM})$ for 24 hours. Our results showed that p53 expression had no any change with $10 \mu \mathrm{M}$ of SP600125 itself but significantly increased when SP600125 was used with 2-DG together (Figure 6c). These findings suggested that the downregulation of $\mathrm{p} 53$ expression by $2-\mathrm{DG}$ might be independent of JNK pathway in our cells. Wild-type p53 is widely known to play an important role in regulating apoptosis. Even though it could be an early event ( 24 hour only), the decreasing wild-type p53 expression by 2-DG could be associated with the decreased apoptosis/necrosis and cisplatin resistance in our cells.
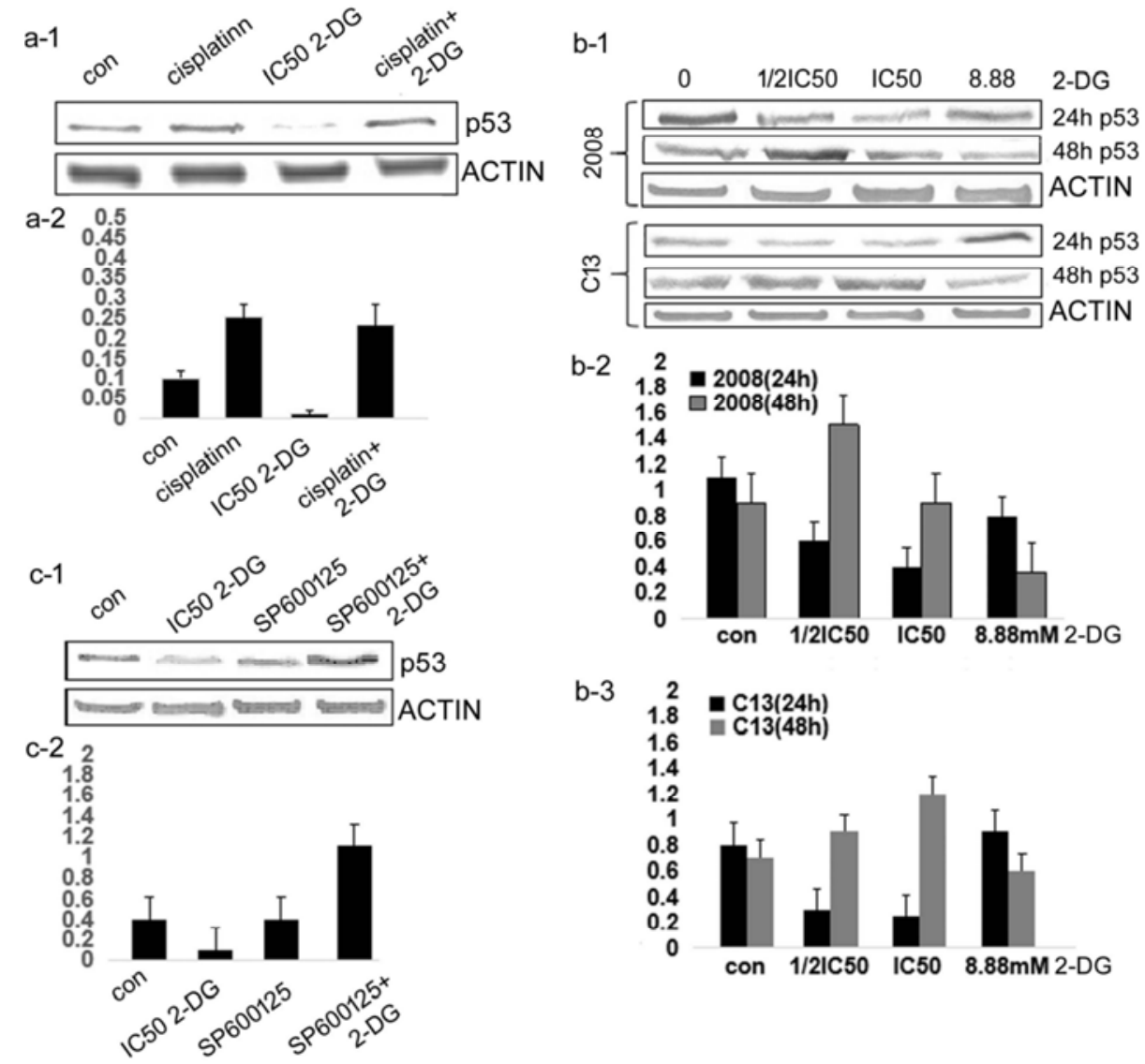

Figure 6. Effect of 2-DG on p53 expression by western blotting analysis. (a) Cisplatin induced p53 expression but 2-DG inhibited p53 expression in 2008 cells. Cisplatin reversed the inhibiting effect of 2-DG on p53 expression. a-1 bands; a-2 densitometry; (b) p53 expression decreased in 2008 and C13 cells at lower (1/2 IC50 and IC50) concentrations at 24-hour treatment; At higher concentration (8.88mM), p53 expression decreased in sensitive 2008 cells but increased in resistant $C 13$ cells. When the cells were treated for 48 hours, p53 expression increased at lower concentrations (1/2 IC50 and IC50) but decreased at higher 8.88mM.b-1 bands; b-2, b-3 densitometry for 2008 and C13 cells at 24 and 48 hours. (c) JNK inhibitor SP600125 significantly reversed the expression inhibition of 533 by 2-DG when combined with 2-DG at 2.5mM in 2008 cells. c-1: bands; c-2 densitometry. 


\section{Discussion}

Cisplatin and carboplatin are widely used for treatment of many solid tumors including cervical cancer. However, the therapeutic outcome is often disappointing due to relapse to resistant disease. During the recent decade, 2-DG has been found to be able to inhibit the growth of tumor cells in vitro [1]. Several clinical trials were also conducted to evaluate its effectiveness for cancer treatment alone or in combination with other chemotherapeutic drugs but finally did not get promising results $[2,3]$. Here we showed for the first time that 2-DG could significantly up-regulate the expression of DDHs and increase cisplatin resistance in human cervical cancer cells.

The JNK/p38 pathway was previously demonstrated to be involved in cisplatin cytotoxicity in 2008 and C13 cells [22]. A relationship between cisplatin treatment and phosphorylation of JNK and p38 was shown with phosphorylation being greater in the sensitive cell lines as opposed to the resistant ones following 24-hour cisplatin treatment. The phosphorylation of $\mathrm{JNK} / \mathrm{p} 38$ consequently activates downstream events inducing apoptosis/necrosis and
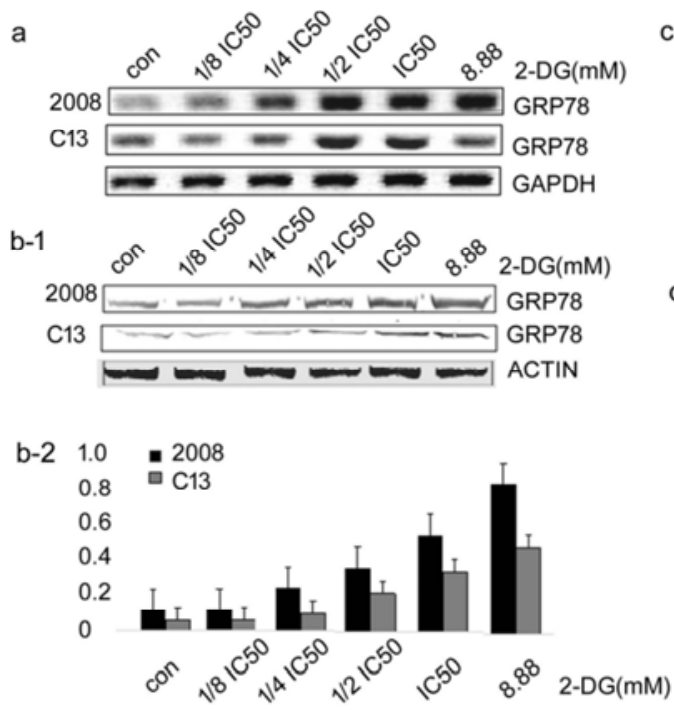

cytosensitivity to cisplatin [22]. To try to elucidate the mechanism of 2-DG-induced DDH over-expression and the decreased apoptosis/necrosis, we detected the JNK activation. Similar to cisplatin, 2-DG could also activate JNK alike. However, when cells were treated with 2-DG and cisplatin together, 2-DG significantly attenuated cisplatininduced JNK phosphorylation, which implied the mechanism for cisplatin resistance triggered by 2-DG. The role of JNK in apoptosis may stem from its ability to regulate the function of p53. In non-stressed state, it is found that JNK associates with p53 and targets it for ubiquitination and degradation [23]. When cells are exposed to stress or DNA damage, the phosphorylated JNK activates p53 and finally induces apoptosis/necrosis. These 2008 and C13 cells express wildtype p53. It has been reported that higher level of wild-type p53 enhances the apoptotic death of prostate cancer cell lines PC-3 and DU-145 [24]. Our study found that 2-DG downregulated wild-type p53 expression at lower concentration (IC50) for 24-hour treatment, which could have subsequently explained the decreased apoptosis/necrosis in 2-DG-induced cisplatin resistance.

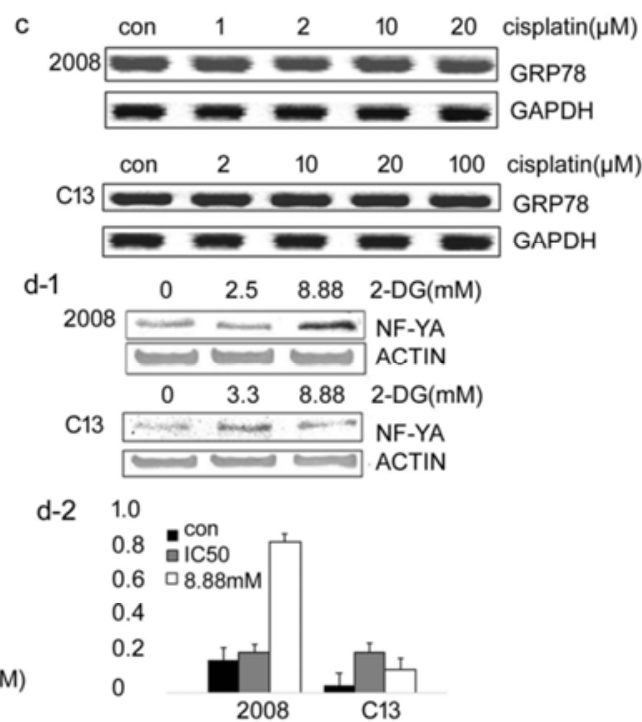

Figure 7. Effect of 2-DG on GRP78 mRNA and protein expression by RT-PCR and western blotting analysis. (a) GRP78 mRNA levels in 2008 and C13 cells in a dose-dependent mode by RT-PCR; (b) GRP78 protein expression up-regulated by 2-DG at increasing concentrations for 6-hour treatment; $b$ - 1 bands; $b$ - 2 densitometry; (c) Cisplatin effect on GRP78 mRNA by RT-PCR in both 2008 and C13 cells. (d) 2-DG induced NF-YA expression by western blotting after 24hour treatment in 2008 and $C 13$ cells. $d-1$ bands; $d-2$ densitometry.

The underlying mechanism of these cellular responses to 2-DG alone or combined with cisplatin is unknown. Traditionally, GRP78 up-regulation has been regarded as the hallmark of the endoplasmic reticulum (ER) stress and unfolded protein response (UPR) on 2-DG treatment [25], we also found GRP78 expression up-regulated in our cells in a dose-dependent mode by $2-\mathrm{DG}$ in our cells (Figure $7 \mathrm{a}, 7 \mathrm{~b}$ ). In multiple tumor types including lung, bladder, stomach, breast, gastric, and epidermoid carcinoma, GRP78 overexpression has been found to confer resistance to a wide variety of chemotherapeutic agents, and knockdown of GRP78 sensitizes the tumor cells to drug treatment $[26,27]$.
So besides of DDHs, GRP78 over-expression by 2-DG in our cells might also contribute to drug resistance. By RT-PCR our preliminary results did not found that cisplatin could induce any change of GRP78 mRNA (Figure 7c). Furthermore, we also found that 2-DG could cause overexpression of HO-1, thioredoxin1, and GSTpi in our cells (data not shown here). All of these proteins have been well known to be associated with cancer chemoresistance. So all in all our findings suggested that 2-DG could cause changes of a serial of other drug resistance related genes, which could also at least partially confer the increasing chemoresistance. We previously found that the transcription factor (NF-Y) 
preferentially bound to the inverted CCAAT box at 109ATTGG-105 of the DDH-1 gene. A two-fold increase with cisplatin treatment on transcription activity was found with 2008 cells [28]. Since 2-DG increases DDH1 expression and the CCAAT box has been more and more focused on as a general transcription regulation site [28], we would like to check whether 2-DG could regulate NF-YA and consequently affect its binding activity to DDH proximal promoter. Our preliminary result showed that $2-\mathrm{DG}$ at $8.88 \mathrm{mM}$ significantly increased NF-YA protein expression in 2008 cells and slightly increased in $\mathrm{C} 13$ cells at $\mathrm{IC} 50 \quad(3.3 \mathrm{mM})$ concentration (Figure 7d). So the effect of 2-DG on DDHs gene transcription regulation is also under way in our laboratory.

Hence in summary, since the precise molecular mechanisms of 2-DG treatment are not clearly known, we would ask the question whether 2-DG is safe to be used clinically or whether the benefits from 2-DG combination are necessarily over the potential risks. Based on the findings in this study, we provided a cautionary note and highlighted 2DG might significantly cause cisplatin resistance and inhibit apoptosis by inducing DDHs over-expression.

\section{Acknowledgements}

The work was supported by the National Institutes of Health to Dr. Henry Simpkins [Grant R01-CA098804, Funding Agency: National Cancer Institute].

\section{Conflict of Interest}

The authors declare that they have no conflicts of interest.

\section{References}

[1] Kang HT, Hwang ES. 2-Deoxyglucose: An anticancer and antiviral therapeutic, but not anymore a low glucose mimetic. Life Sciences 2006; 78: 1392-1399.

[2] Maher JC, Wangpaichitr M, Savaraj N, Kurtoglu M, Lampidis TJ. Hypoxia-inducible factor-1 confers resistance to the glycolytic inhibitor 2-deoxy-D-glucose. Mol Cancer Ther 2007; 6: 732-741.

[3] Dwarakanath BS, Singh D, Banerji AK, Sarin R, Venkataramana NK, Jalali R, Vishwanath PN, Mohanti BK, Tripathi RP, Kalia VK, Jain V. Clinical studies for improving radiotherapy with 2-deoxy-D-glucose: present status and future prospects. J Cancer Res Ther 2009; 1: S21-26.

[4] Ledoux S, Yang R, Friedlander G, Laouari D. Glucose depletion enhances P-glycoprotein expression in hepatoma cells: role of endoplasmic reticulum stress response. Cancer Res 2003; 63: 7284-7290.

[5] Qian X, Xu W, Xu J, Shi Q, Li J, Weng Y, Jiang Z, Feng L, Wang X, Zhou J, Jin H. Enolase 1 stimulates glycolysis to promote chemoresistance in gastric cancer. Oncotarget 2017; 8: 47691-47708.

[6] Park GB, Chung YH, Kim D. 2-Deoxy-D-glucose suppresses the migration and reverses the drug resistance of colon cancer cells through ADAM expression regulation. Anticancer Drugs 2017; 28: 410-420.

[7] Xue C, Wang C, Sun Y, Meng Q, Liu Z, Huo X, Sun P, Sun H, Ma X, Ma X, Peng J, Liu K. Targeting P-glycoprotein function, p53 and energy metabolism: Combination of metformin and 2-deoxyglucose reverses the multidrug resistance of MCF-7/Dox cells to doxorubicin. Oncotarget 2017; 8: 8622-8632.

[8] Xue C, Wang C, Liu Q, Meng Q, Sun H, Huo X, Ma X, Liu Z, Ma X, Peng J, Liu K. Targeting P-glycoprotein expression and cancer cell energy metabolism: combination of metformin and 2-deoxyglucose reverses the multidrug resistance of K562/Dox cells to doxorubicin. Tumour Biol 2016; 37: 85878597.

[9] Pang YY, Wang T, Chen FY, Wu YL, Shao X, Xiao F, Huang HH, Zhong H, Zhong JH. Glycolytic inhibitor 2-deoxy-dglucose suppresses cell proliferation and enhances methylprednisolone sensitivity in non-Hodgkin lymphoma cells through down-regulation of HIF- $1 \alpha$ and c-MYC. Leuk Lymphoma 2015; 56: 1821-1830.

[10] Xu Y, Wang Q, Zhang L, Zheng M. 2-Deoxy-D-glucose enhances TRAIL-induced apoptosis in human gastric cancer cells through downregulating JNK-mediated cytoprotective autophagy. Cancer Chemother Pharmacol 2018; 81: 555-564.

[11] Pawłowski KM, Mucha J, Majchrzak K, Motyl T, Król M. Expression and role of PGP, BCRP, MRP1 and MRP3 in multidrug resistance of canine mammary cancer cells. BMC Vet Res 2013; 9: 119.

[12] Deng HB, Adikari M, Parekh HK, Simpkins H. Increased expression of dihydrodiol dehydrogenase induces resistance to cisplatin in human cervicalcarcinoma cells. J Biol Chem 2002; 277: $15035-15043$.

[13] Chen J, Adikari M, Pallai R, Parekh HK, Simpkins H. Dihydrodiol dehydrogenase regulates the generation of reactive oxygen species and the development of cisplatin resistance in human cervicalcarcinoma cells. Cancer Chemother. Pharmacol 2008; 61: 979-987.

[14] Chen J, Solomides C, Parekh H, Simpkins F, Simpkins H. Cisplatin resistance in human cervical, ovarian and lung cancer cells. Cancer Chemother Pharmacol 2015; 75: 12171227.

[15] Deng HB, Adikari M, Parekh HK, Simpkins H. Ubiquitous induction of resistance to platinum drugs in human ovarian, cervical, germ cell and lung carcinoma tumor cells overexpressing isoforms 1 and 2 of dihydrodriol dehydrogenase. Cancer Chemother Pharmacol 2004; 54: 301-307.

[16] Chen YJ, Yuan GC, Chan KC, et al. over-expression of dihydrodiol dehydrogenase is associated with cisplatin-based chemotherapy resistance in cervical cancer patients. Gynecol Oncol 2005; 97: 110-117.

[17] Hsu NY, Ho HC, Chow KC, Lin TY, Shih CS, Wang LS, Tsai $\mathrm{CM}$. over-expression of dihydrodiol dehydrogenase as a prognostic marker of non-small cell lung cancer. Cancer Res 2001; 61: 2727-2731.

[18] Parekh HK, Simpkins H. The differential expression of cytokeratin 18 in cisplatin-sensitive and resistant human cervicaladenocarcinoma cells and its association with drug sensitivity. Cancer Res 1995; 55: 5203-5206. 
[19] Simons AL, Ahmad IM, Mattson DM, Dornfeld KJ, Spitz DR. 2-Deoxy-D-glucose combined with cisplatin enhances cytotoxicity via metabolic oxidative stress in human head and neck cancer cells. Cancer Res 2007; 67: 3364-3370.

[20] Mingo-Sion AM, Marietta PM, Koller E, Wolf DM, Van Den Berg CL. Inhibition of JNK reduces G2/M transit independent of p53, leading to endoreduplication, decreased proliferation, and apoptosis in breast cancer cells. Oncogene 2004; 23: 596604.

[21] Shankar E, Basu C, Adkins B, Siede W, Basu A. NSC109268 potentiates cisplatin-induced cell death in a p53-independent manner. J Mol Signal 2010; 5: 4-11.

[22] Gebauer A, Mirakhur B, Nguyen A, Shue SK, H. Simpkins H, Dhanasekaran N. Cisplatin resistance involving the defective processing of MEKKI in human cervicaladenocarcinoma 2008/C13 cells. Int Jnl Oncology 2000; 16: 321-325.

[23] Fuchs SY, Adler V, Buschmann T, Yin Z, Wu X, Jones SN, Ronai Z. JNK targets p53 ubiquitination and degradation in nonstressed cells. Genes Dev 1998; 12: 2658-2663.

[24] Ahmad IM, Abdalla MY, Aykin-Burns N, Simons AL, Oberley LW, Domann FE, Spitz DR. 2-Deoxyglucose combined with wild-type p53 over-expression enhances cytotoxicity in human prostate cancer cells via oxidative stress. Free Radic Biol Med 2008; 44: 826-834.
[25] Xi H, Kurtoglu M, Liu H, Wangpaichitr M, You M, Liu X, Savaraj N, Lampidis TJ.2-Deoxy-D-glucose activates autophagy via endoplasmic reticulum stress rather than ATP depletion. Cancer Chemother Pharmacol 2011; 67: 899-910.

[26] Lee AS. GRP78 induction in cancer: therapeutic and prognostic implications. Cancer Res 2007; 67: 3496-3499.

[27] Ni M, Zhang Y, Lee AS. Beyond the endoplasmic reticulum: atypical GRP78 in cell viability, signalling and therapeutic targeting. Biochem J 2011; 434: 181-188.

[28] Pallai R, H Simpkins, Jianli Chen, HK Parekh. Nuclear Factor $\mathrm{Y}$ regulates the transcription of the human aldoketoreductase AKR1C1 gene. Gene 2010; 459: 11-23.

[29] Chan DW, Liu VW, Tsao GS, Yao KM, Furukawa T, Chan KK, Ngan HY. Loss of MKP3 mediated by oxidative stress enhances tumorigenicity and chemoresistance of cervical cancer cells. Carcinogenesis 2008; 29: 1742-50.

[30] Deshpande VS, Kehrer James P. Mechanisms of Nacetylcysteine-driven enhancement of MK886-induced apoptosis. Cell Bil Toxicol 2006; 22: 303-311.

[31] Rakshit S, Bagchi J, Mandal L, Paul K, et al. N-acetyl cysteine enhances imatinib-induced apoptosis of Bcr-Abl+ cells by endothelial nitric oxide synthase-mediated production of nitric oxide. Apoptosis 2009; 14: 298-308. 